\title{
Guidelines for reporting methods to estimate metabolic rates by aquatic intermittent-flow respirometry
}

\author{
Shaun S. Killen ${ }^{1, *}$, Emil A. F. Christensen ${ }^{1}$, Daphne Cortese ${ }^{1,2}$, Libor Závorka ${ }^{1,3}$, Tommy Norin $^{4}$, Lucy Cotgrove ${ }^{1}$, \\ Amélie Crespel $^{5}$, Amelia Munson ${ }^{1,6}$, Julie J. H. Nati ${ }^{7}$, Magdalene Papatheodoulou ${ }^{1,8}$ and David J. McKenzie ${ }^{7}$
}

\begin{abstract}
Interest in the measurement of metabolic rates is growing rapidly, because of the importance of metabolism in advancing our understanding of organismal physiology, behaviour, evolution and responses to environmental change. The study of metabolism in aquatic animals is undergoing an especially pronounced expansion, with more researchers utilising intermittent-flow respirometry as a research tool than ever before. Aquatic respirometry measures the rate of oxygen uptake as a proxy for metabolic rate, and the intermittent-flow technique has numerous strengths for use with aquatic animals, allowing metabolic rate to be repeatedly estimated on individual animals over several hours or days and during exposure to various conditions or stimuli. There are, however, no published guidelines for the reporting of methodological details when using this method. Here, we provide the first guidelines for reporting intermittent-flow respirometry methods, in the form of a checklist of criteria that we consider to be the minimum required for the interpretation, evaluation and replication of experiments using intermittent-flow respirometry. Furthermore, using a survey of the existing literature, we show that there has been incomplete and inconsistent reporting of methods for intermittent-flow respirometry over the past few decades. Use of the provided checklist of required criteria by researchers when publishing their work should increase consistency of the reporting of methods for studies that use intermittent-flow respirometry. With the steep increase in studies using intermittent-flow respirometry, now is the ideal time to standardise reporting of methods, so that - in the future - data can be properly assessed by other scientists and conservationists.
\end{abstract}

KEY WORDS: Metabolic rate, Fish, Oxygen, Aerobic metabolism, Replication, Experimental design

${ }^{1}$ Institute of Biodiversity, Animal Health and Comparative Medicine, College of
Medical, Veterinary and Life Sciences, Graham Kerr Building, University of
Glasgow, Glasgow G12 8QQ, UK. ${ }^{2}$ PSL Université Paris: EPHE-UPVD-CNRS, USR
3278 CRIOBE, BP 1013, 98729 Papetoai, Moorea, French Polynesia.
${ }^{3}$ WasserCluster Lunz-Inter-university Centre for Aquatic Ecosystem Research,
A-3293 Lunz am See, Austria. ${ }^{4}$ DTU Aqua: National Institute of Aquatic Resources,
Technical University of Denmark, 2800 Kgs. Lyngby, Denmark. ${ }^{5}$ Department of
Biology, University of Turku, 20500 Turku, Finland. ${ }^{6}$ Department of Environmental
Science and Policy, University of California, Davis, CA 95615, USA. ${ }^{7}$ MARBEC,
Université Montpellier, CNRS, Ifremer, IRD, 34000 Montpellier, France. ${ }^{8}$ Enalia
Physis Environmental Research Centre (ENALIA), 2101 Nicosia, Cyprus.
*Author for correspondence: (shaun.killen@glasgow.ac.uk)

(D) S.S.K., 0000-0003-4949-3988; T.N., 0000-0003-4323-7254; D.J.M., 0000-00030961-9101

This is an Open Access article distributed under the terms of the Creative Commons Attribution License (https://creativecommons.org/licenses/by/4.0), which permits unrestricted use, distribution and reproduction in any medium provided that the original work is properly attributed.

Handling Editor: Charlotte Rutledge

\section{Introduction}

Estimation of the metabolic rates of animals has been a core element of research in comparative physiology for decades (Kleiber, 1947; Rolfe and Brown, 1997). Metabolic rates have also been studied in the context of physiological and behavioural ecology (Killen et al., 2013; Mathot et al., 2019; Metcalfe et al., 2016), as well as in the examination of broad ecological phenomena across levels of biological organisation (Brown et al., 2004; Hatton et al., 2019). The study of metabolic rates has recently received even greater attention because of the need to understand plastic and evolutionary responses to environmental change, particularly in aquatic ecosystems (Jutfelt et al., 2018; Norin and Metcalfe, 2019; Pörtner et al., 2017). This increased interest has occurred alongside technological advances in methods of respirometry, which measure rates of gas exchange between an organism and their environment. In particular, the rate at which an organism takes up oxygen from its environment is expected to be related stoichiometrically to rates of ATP production by mitochondrial oxidative phosphorylation and, therefore, is considered a proxy for metabolic rate (Nelson, 2016). The rise of commercially available components has further facilitated the estimation of metabolic rates by respirometry in a variety of organisms. These factors have been particularly consequential for respirometry on animals that breathe water because, historically, this has been more difficult to conduct compared with respirometry on air-breathers. As such, there are more scientists using aquatic respirometry as a research tool than ever before, with more than $60 \%$ of the papers in this field being generated in the past 10 years alone (Fig. S1).

We begin this Commentary by describing methods of aquatic respirometry, particularly focusing on intermittent-flow respirometry, and go on to discuss the need to standardise the reporting of methods for studies using this research technique. We then provide a checklist of 53 essential methodological criteria that should be reported in all studies using intermittent-flow respirometry. We also present results of a literature survey, demonstrating the extent to which these various criteria have traditionally been inadequately reported. Finally, we provide a downloadable form (Table S1) that we encourage researchers to complete and include with future manuscripts for studies using intermittent-flow respirometry, to clearly and concisely summarise key methodological details.

\section{Intermittent-flow respirometry}

The most widely accepted method for measuring rates of oxygen uptake in water-breathing organisms is automated intermittent-flow respirometry (Steffensen, 1989; Svendsen et al., 2016a), also sometimes referred to as intermittent-closed respirometry (Norin and Gamperl, 2018). Although the technique has mainly been developed for use on fishes, it is suitable for almost any waterbreathing organism (Fig. 1). An animal is placed in a gasimpermeable respirometry chamber equipped with an oxygen 


\section{Box 1. Metabolic traits that can be estimated using intermittent-flow respirometry \\ Standard metabolic rate (SMR)}

This is the minimum rate of ATP use required to sustain life, in the absence of voluntary muscular movements and digestion/absorption of nutrients (Chabot et al., 2016). With intermittent-flow respirometry, SMR is estimated by collecting measurements of oxygen uptake over an extended period on an undisturbed animal, after acclimatation to the respirometer, and then extracting a value for SMR using one of a number of statistical methods (Chabot et al., 2016). In ectotherms, SMR is especially likely to change with environmental temperature (Chabot et al., 2016; Schulte, 2015), so temperature must be reported.

Routine metabolic rate (RMR)

This is the average oxygen uptake rate of a post-absorptive animal, where spontaneous activity contributes to ATP use and, therefore, oxygen demand (Chabot et al., 2016). It is typically measured as the average of the oxygen uptake rate measurements that are collected to estimate SMR, although some portions of the dataset may not be considered; for example, high rates of oxygen uptake when the animal is stressed by handling for placement in the respirometer (Chabot et al., 2016; Steffensen, 1989). The RMR can, in theory, lie anywhere between SMR and MMR, but it is expected to be closer to SMR if animals are undisturbed (Chabot et al., 2016). RMR is often used to infer a metabolic response to a stimulus or stressor (e.g. perceived predator threat) (Hall and Clark, 2016; Palacios et al., 2016). Also note that the abbreviation 'RMR' is sometimes used to refer to 'resting metabolic rate', a term often used as a less strict equivalent of SMR.

Maximum metabolic rate (MMR)

This is the maximum rate of oxygen uptake that an animal can achieve to create ATP aerobically (Norin and Clark, 2016). Two main methods are used to estimate MMR in fishes (Killen et al., 2017; Norin and Clark, 2016): they can be exposed to incremental swim speeds in a swimtunnel respirometer, with MMR taken as the highest rate of oxygen uptake before fatigue, or they can be chased to exhaustion in a tank and then placed in a respirometer chamber, with MMR taken as the highest rate of oxygen uptake during recovery. There is no consensus on how best to measure MMR (Killen et al., 2017; Norin and Clark, 2016; Zhang et al., 2020).

\section{Aerobic metabolic scope (AS)}

This is the maximum capacity to supply oxygen to sustain metabolic activities beyond SMR (Fry, 1971). Absolute AS is calculated as MMR minus SMR, whereas factorial AS is MMR divided by SMR; the choice of which is more appropriate may depend on the research question of interest (Halsey et al., 2018).

sensor, and is then exposed to periodic, alternating 'closed' and 'flush' phases. During the closed phase, the respirometer is effectively sealed and there is a decline in dissolved oxygen in the water due to oxygen uptake by the animal. With traditional closed respirometry, the decline in oxygen concentration is measured while the animal is in a continually sealed chamber, and this containment can eventually cause hypoxia and accumulation of waste products in the respirometer, which can influence the resulting measurements of oxygen uptake. With intermittent-flow respirometry, however, this is avoided by the flush phase, during which the respirometer is flushed with clean, aerated water, which replaces oxygen and removes metabolic wastes.

The alternation of the closed and flush phases means that realtime rates of oxygen uptake can be recorded in successive closed phases over extended periods, with animals left undisturbed. This can provide an accurate picture of dynamic changes in oxygen uptake over time. These changes might be due to factors such as initial handling stress, circadian rhythms and metabolic costs of digestion, among others (Jourdan-Pineau et al., 2010; Steffensen, 1989). Using this technique can also reveal when the undisturbed animal is potentially functioning at basal rates of metabolism, denoted as standard metabolic rate (SMR) for ectotherms (Box 1) or when it is performing some defined level of activity or type of behaviour, often referred to as routine metabolic rate (RMR, Box 1). This ability to track changes in oxygen uptake rate in real time is a major improvement over the technique of flow-through respirometry (Ultsch et al., 1980), where there is a continuous flow of water through a respirometry chamber and oxygen uptake is measured by comparing the difference in oxygen concentration at inflow and outflow. This can result in large measurement error when the difference in dissolved oxygen at the inflow and outflow are small. Furthermore, with flow-through respirometry, changes in oxygen concentration at the outflow lag behind changes in metabolic activity of the animal because of a reservoir, or washout, effect. This lag depends upon the dilution factor, which is the ratio of respirometer volume to rate of water flow through it (see Steffensen, 1989 for a detailed explanation). The consequence is that flow-through respirometry can only be used to measure relatively steady physiological states (Steffensen, 1989).

Intermittent-flow respirometry is, therefore, the best available method to estimate metabolic rate in water-breathing animals and should be utilised whenever possible. Notably, measures of SMR and RMR can be coupled with measures of aerobic maximum metabolic rate (MMR, Box 1) to estimate aerobic scope (AS, Box 1). Given this wide range of applications and the relative robustness of intermittent-flow respirometry, it has become an extremely popular choice of methodology among comparative physiologists, including researchers who are new to the estimation of metabolic rates via measurement of respiratory gas exchange.

\section{A need for the standardisation of methods}

Despite its increasingly wide usage, there are no guidelines for reporting the methods used in intermittent-flow respirometry. There are several guides to best practice for measuring and analysing various types of metabolic rates (Chabot et al., 2016; Norin and Clark, 2016; Steffensen, 1989; Svendsen et al., 2016a; Clark et al., 2013), but details can vary widely among researchers, and the quality and values of the data generated using intermittent-flow respirometry is completely dependent on myriad methodological decisions made throughout the experiment, from equipment setup to data collection and analysis (Steffensen, 1989; Svendsen et al., 2016a). Equally important is that the reporting of methods also differs greatly across peer-reviewed studies, with important details often not mentioned. A lack of methodological detail, or inaccurate and vague descriptions, are problematic because: (1) they make it difficult for readers to evaluate data reliability and judge the interpretation of results; (2) they can give a misleading impression of what was done; (3) they hinder replication of the experiments; and (4) data on metabolic rates are increasingly used in metaanalyses (Holtmann et al., 2017; Jerde et al., 2019; Killen et al., 2016), so proper methodological documentation would be useful to allow researchers to understand sources of residual variation across studies. In addition, a standard set of guidelines for reporting methods in intermittent-flow respirometry studies would make it easier for journal editors and reviewers to decide whether a given study warrants publication in the first place. Finally, a list of important methodological details would be extremely useful for students and researchers who are new to this field of research and are using this technique for the first time.

Thus, we believe that researchers using intermittent-flow respirometry would benefit from a standardised, publicly available checklist of details that should be included when describing their 


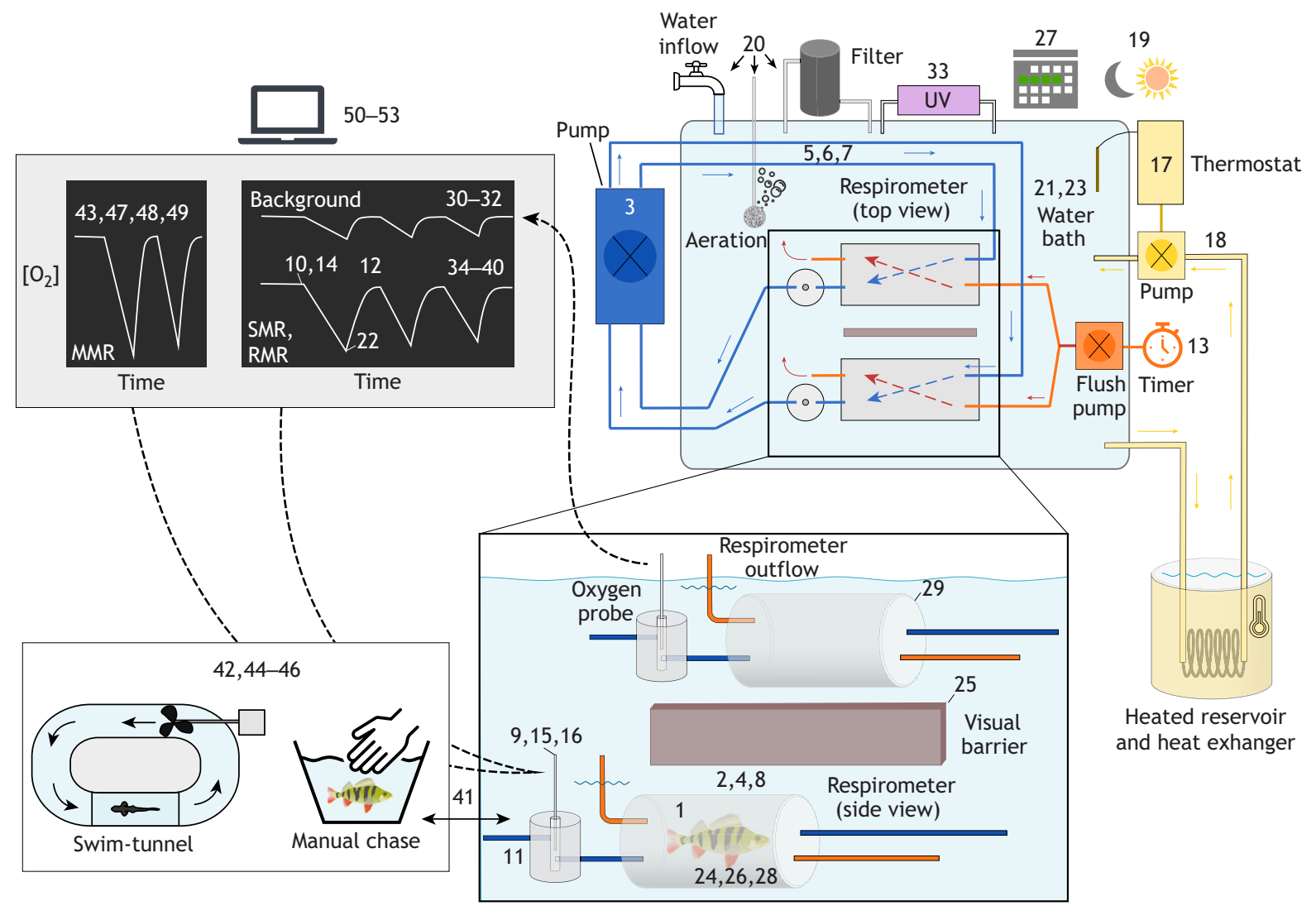

Fig. 1. Schematic of a typical intermittent-flow respirometry setup. Numbers correspond to the criteria listed in Table 1 and show the general location of each criterion within the setup. The top right depicts a top-down view of the setup; the enlarged box below presents a more detailed side-view of two respirometers (one containing a fish and the other being an empty chamber for measuring background respiration). Orange items (excluding the sun in the top corner, which represents photoperiod) are those used for periodically flushing the respirometer with clean, aerated water from the surrounding bath, with orange lines representing tubing in this flushing circuit. Dark blue represents the mixing circuit and associated tubing. Note that in this scheme, mixing is performed with a multi-channel peristaltic pump, but mixing can also be achieved with a single-channel pump or stir-bar, depending on the size and shape of the respirometers. Yellow represents elements associated with temperature control; here, temperature is maintained using a thermostat that controls a pump to direct water through a heat exchanger within a heated reservoir whenever temperature within the bath drops below the setpoint. The box to the lower left depicts methods for exercising fish for estimates of maximum metabolic rate. The top left box represents computer-based data collection and analyses. Dashed black arrows represent transmission of data from oxygen probes to computer for analyses. Refer to Svendsen et al. (2016a,b) for more information on setup components and overall system functioning. SMR, standard metabolic rate; RMR, routine metabolic rate; MMR, maximum metabolic rate; UV, ultraviolet.

methods, to prevent further under-reporting of important elements. The use of reporting guidelines for methods, in the form of checklists or flow-charts (Carp, 2012; Cowger et al., 2020; Michel et al., 2020), is widespread across the biological sciences, and is long overdue in comparative physiology and especially respirometry. With the steady increase in the number of published studies using respirometry (Fig. S1), now is the ideal time to establish and institute such standard guidelines for accurate methodological reporting.

\section{A checklist for reporting methods using intermittent-flow respirometry}

Focusing on studies with fishes, here we provide a checklist of 53 criteria that are essential for understanding, interpreting and replicating experiments using aquatic intermittent-flow respirometry (Table 1; Fig. 1). We aim to provide an explicit list of details that can be referenced when writing or evaluating research papers, or when planning new studies. Although the criteria are focussed on studies with fishes, most criteria could be applied to studies with any aquatic organism. In addition to being included as Table 1 of this article, we also provide a downloadable form that authors can use to easily list each criterion in a table format, which we suggest can be submitted as supplementary material with manuscripts to accompany contextual descriptions in the main text of published research papers (Table S1).

We have restricted our criteria to cover methods involved in the most common forms of aquatic intermittent-flow respirometry, namely, the measurement of SMR, RMR, MMR and aerobic metabolic scope (AS) (Box 1). Methods unique to other applications, such as protocols for measuring critical oxygen tension $\left(P_{\text {crit }}\right)$, are not specifically covered here (Claireaux and Chabot, 2016; Ultsch and Regan, 2019), but the checklist can still be used as a guide to ensure that the most basic criteria of respirometry are met when carrying out these more specialised procedures.

The criteria are divided into six categories, based on whether they describe the materials and conditions used in any given study, or are details of the various measurements that can be conducted using intermittent-flow respirometry. More detail on each of the categories in the checklist is given below.

\section{Equipment, materials and setup}

It is necessary to provide adequate details of the specific equipment used in the study and the way these components are assembled to measure animal oxygen uptake. Equipment and setup details are important because there is a wide array of available oxygen sensors, 
Table 1. Checklist of criteria that should be reported when using aquatic intermittent-flow respirometry to estimate SMR/RMR or MMR, along with detailed descriptions of each criterion. Also shown is the prevalence of each criterion in the existing literature

\begin{tabular}{|c|c|c|c|c|}
\hline Number & Criterion and category & $\begin{array}{l}\text { Prevalence } \\
\text { (\% papers) }\end{array}$ & Description & References \\
\hline \multicolumn{5}{|c|}{ Equipment, materials and setup } \\
\hline 1 & $\begin{array}{l}\text { Provide body mass of animals at } \\
\text { time of respirometry }\end{array}$ & 71.2 & $\begin{array}{l}\text { Metabolic rate is strongly correlated with body mass in animals. Studies } \\
\text { should specify that mass was measured immediately before or after } \\
\text { respirometry and not simply state mass upon arrival to the laboratory or } \\
\text { time of capture. }\end{array}$ & $\begin{array}{l}\text { Clarke and } \\
\text { Johnston, 1999; } \\
\text { Jerde et al., } 2019\end{array}$ \\
\hline 2 & $\begin{array}{l}\text { Provide volume of empty } \\
\text { respirometer }\end{array}$ & 86.1 & $\begin{array}{l}\text { Chamber volume can affect factors such as confinement stress and the time } \\
\text { taken to measure a decrease in water dissolved oxygen. See criterion } 4 \\
\text { (below). }\end{array}$ & $\begin{array}{l}\text { Svendsen et al., } \\
\text { 2016b }\end{array}$ \\
\hline 3 & $\begin{array}{l}\text { Describe how chamber mixing } \\
\text { was achieved }\end{array}$ & 47.6 & $\begin{array}{l}\text { Chamber mixing is crucial for homogenising dissolved oxygen within the } \\
\text { system. This is often achieved with an external in-line pump, peristaltic } \\
\text { pump or stir-bar. Relying on animal activity to mix the water is not } \\
\text { sufficient. }\end{array}$ & $\begin{array}{l}\text { Clark et al., 2013; } \\
\text { Rodgers et al., } \\
2016\end{array}$ \\
\hline 4 & $\begin{array}{l}\text { Provide ratio of net respirometer } \\
\text { volume (plus any associated } \\
\text { tubing in mixing circuit) to } \\
\text { animal body mass }\end{array}$ & 12.0 & $\begin{array}{l}\text { This ratio should be explicitly stated, ideally as a range, because it will vary } \\
\text { among fish and respirometers of different sizes. A chamber that is too } \\
\text { small may increase animal stress due to confinement. Larger } \\
\text { respirometer sizes will require longer closed cycles to provide a } \\
\text { measurable decline in oxygen, and may also reduce the ability to } \\
\text { accurately measure maximum metabolic rate owing to a lag between } \\
\text { when the fish consumes oxygen and when that decline is detected by the } \\
\text { system. }\end{array}$ & $\begin{array}{l}\text { Svendsen et al., } \\
\text { 2016b }\end{array}$ \\
\hline 5 & $\begin{array}{l}\text { Provide material of tubing used in } \\
\text { any mixing circuit }\end{array}$ & 15.5 & $\begin{array}{l}\text { Some materials are gas permeable or absorb or release oxygen. Silicone is } \\
\text { particularly permeable and should be avoided as the mixing (recirculation) } \\
\text { circuit. }\end{array}$ & Stevens, 1992 \\
\hline 6 & $\begin{array}{l}\text { Provide volume of tubing in any } \\
\text { mixing circuit }\end{array}$ & 20.9 & $\begin{array}{l}\text { The volume of tubing in any mixing circuit should be minimised, to avoid } \\
\text { adding unnecessary volume and providing surfaces for microbial } \\
\text { adherence. }\end{array}$ & $\begin{array}{l}\text { Svendsen et al., } \\
\qquad 2016 a\end{array}$ \\
\hline 7 & $\begin{array}{l}\text { Confirm volume of tubing in any } \\
\text { mixing circuit is included in } \\
\text { calculations of oxygen uptake } \\
\text { rates }\end{array}$ & 14.5 & $\begin{array}{l}\text { Tubing volume should always be added to the total volume of the } \\
\text { respirometer system when calculating rates of oxygen uptake. }\end{array}$ & $\begin{array}{l}\text { Svendsen et al., } \\
\qquad 2016 a\end{array}$ \\
\hline 8 & $\begin{array}{l}\text { Provide material of respirometer } \\
\text { (e.g. glass, acrylic etc.) }\end{array}$ & 57.2 & Some materials are gas permeable or absorb or release oxygen. & Stevens, 1992 \\
\hline 9 & $\begin{array}{l}\text { Provide type of oxygen probe } \\
\text { and data recording }\end{array}$ & 89.4 & $\begin{array}{l}\text { Different probe types have different response times, pressure sensitivity and } \\
\text { signal quality (level of noise). Some probe types (e.g. galvanic) have their } \\
\text { own oxygen consumption that should be corrected for. }\end{array}$ & Klimant et al., 1995 \\
\hline 10 & $\begin{array}{l}\text { Provide sampling frequency of } \\
\text { water-dissolved oxygen }\end{array}$ & 48.6 & $\begin{array}{l}\text { The number of readings per unit time may affect estimates and } r^{2} \text { values of } \\
\text { the slopes for the decrease in dissolved oxygen over time that are used to } \\
\text { calculate oxygen uptake rates. }\end{array}$ & $\begin{array}{l}\text { Chabot et al., 2016; } \\
\text { Clark et al., } 2013\end{array}$ \\
\hline 11 & $\begin{array}{l}\text { Describe placement of oxygen } \\
\text { probe (in mixing circuit or } \\
\text { directly in chamber) }\end{array}$ & 56.7 & $\begin{array}{l}\text { Probe placement may affect lag time between animal oxygen uptake and } \\
\text { detection, the sensitivity to mixing and, depending on the type of probe, } \\
\text { sensitivity to pressure changes in the respirometer. If the probe is placed } \\
\text { within the chamber, the animal may touch it and thus affect recordings, or } \\
\text { even become disturbed. For probes that are directly inside respirometers, } \\
\text { it should be stated whether they are small sensor spots or full-sized } \\
\text { probes. }\end{array}$ & Clark et al., 2013 \\
\hline 12 & $\begin{array}{l}\text { Provide flow rate during flushing } \\
\text { and recirculation, or confirm } \\
\text { that chamber returned to } \\
\text { normoxia during flushing }\end{array}$ & 30.0 & $\begin{array}{l}\text { Knowledge of flow rates in relation to respirometer volume is essential to } \\
\text { evaluate whether flow was sufficient to replenish water oxygen levels } \\
\text { (flush) or mix adequately (recirculation) without being so high as to disturb } \\
\text { the animal. As a rule-of-thumb, it will take } 5 \text { min to fully }(>99 \%) \text { replace the } \\
\text { water in a respirometer when the flow rate is one respirometer volume per } \\
\text { minute. }\end{array}$ & Steffensen, 1989 \\
\hline 13 & $\begin{array}{l}\text { Provide timing of flush/closed } \\
\text { cycles }\end{array}$ & 85.1 & $\begin{array}{l}\text { Knowing the flush/closed timing allows one to evaluate whether oxygen } \\
\text { level returned to normoxia during flushing, and whether declines in } \\
\text { oxygen level during the closed cycle could produce a stable linear } \\
\text { decrease for determination of oxygen uptake rate. Intervals that are too } \\
\text { long may also make it difficult to detect and account for spontaneous } \\
\text { activity during SMR determination. If cycle timing is based on an oxygen } \\
\text { threshold, this should be specified. }\end{array}$ & Steffensen, 1989 \\
\hline 14 & $\begin{array}{l}\text { Provide wait (delay) time } \\
\text { excluded from closed } \\
\text { measurement cycles }\end{array}$ & 53.8 & $\begin{array}{l}\text { Linear decrease in oxygen content is not immediately achieved during the } \\
\text { onset of the closed cycle due to mixing of water within the respirometer } \\
\text { and the response time of the oxygen sensor. }\end{array}$ & $\begin{array}{l}\text { Steffensen et al., } \\
\text { 1984; Svendsen } \\
\text { et al., } 2016 \text { a }\end{array}$ \\
\hline 15 & $\begin{array}{l}\text { Describe frequency and method } \\
\text { of probe calibration (for both } 0 \\
\text { and } 100 \% \text { calibrations) }\end{array}$ & 22.1 & $\begin{array}{l}\text { The calibration of the probe can drift over time, especially for those sensitive } \\
\text { to pressure. }\end{array}$ & \\
\hline
\end{tabular}


Table 1. Continued

\begin{tabular}{|c|c|c|c|}
\hline Number & Criterion and category & $\begin{array}{l}\text { Prevalence } \\
\text { (\% papers) }\end{array}$ & Description \\
\hline 16 & $\begin{array}{l}\text { State whether software } \\
\text { temperature compensation } \\
\text { was used during recording of } \\
\text { water oxygen concentration }\end{array}$ & 18.3 & $\begin{array}{l}\text { Some oxygen probes are more sensitive than others to temperature } \\
\text { fluctuations (e.g. optical sensors are very sensitive), meaning that oxygen } \\
\text { recordings may not be accurate if temperature changes during } \\
\text { respirometry. }\end{array}$ \\
\hline \multicolumn{4}{|c|}{ Measurement conditions } \\
\hline 17 & $\begin{array}{l}\text { Provide temperature during } \\
\text { respirometry }\end{array}$ & 86.1 & $\begin{array}{l}\text { Metabolic rate is strongly affected by environmental temperature in } \\
\text { ectotherms. }\end{array}$ \\
\hline 18 & $\begin{array}{l}\text { State how temperature was } \\
\text { controlled }\end{array}$ & 44.7 & $\begin{array}{l}\text { Different methods of temperature control may generate different levels of } \\
\text { variability around the desired thermal setpoint. }\end{array}$ \\
\hline 19 & $\begin{array}{l}\text { Provide photoperiod during } \\
\text { respirometry }\end{array}$ & 29.0 & $\begin{array}{l}\text { Metabolic rate fluctuates over the course of a } 24-h \text { day and can be affected } \\
\text { by photoperiod. Switching on the light in the experimental room can result } \\
\text { in abruptly increased rates of oxygen uptake. }\end{array}$ \\
\hline 20 & $\begin{array}{l}\text { Describe if (and how) the } \\
\text { ambient water bath was } \\
\text { cleaned and aerated during } \\
\text { measurement of oxygen }\end{array}$ & 38.5 & $\begin{array}{l}\text { Aeration of the ambient bath ensures oxygen in respirometers is replaced } \\
\text { during flushing and removes metabolic } \mathrm{CO}_{2} \text { produced by the animal. } \\
\text { Replacement of water in the ambient bath ensures metabolic wastes such } \\
\text { as ammonia do not accumulate. }\end{array}$ \\
\hline
\end{tabular}

References uptake (e.g. filtration, periodic or continuous water changes)

21 Provide total volume of ambient water bath and any associated reservoirs

22 Provide minimum water oxygen level reached during closed phases

23 State whether chambers were visually shielded from externa disturbance

24 State how many animals were measured during a given respirometry trial (i.e. how many animals were in the same water bath)

25 If multiple animals were measured simultaneously state whether they were able to see each other during measurements

26 Provide duration of animal fasting before placement in respirometer

$27 \quad$ Provide duration of all trials combined (number of days to measure all animals in the study)

28 Provide acclimation time to the laboratory (or time since capture for field studies) before respirometry measurements

40.4 This can inform about the likelihood of accumulation of wastes, and potential difficulties in flushing chambers back to normoxia.

30.9 Reduced oxygen availability (hypoxia) does not affect standard metabolic rate until near-lethal levels (at the so-called critical oxygen tension), but reduces maximum and eventually routine rates of oxygen uptake, especially if it alters animal activity.

45.4 External disturbance may cause agitation and stress, potentially altering rates of oxygen uptake.

63.9 This provides an idea of the biological load in the respirometry setup and potential interdependence of animals measured in a single block of measurements.

14.9 Visual or olfactory cues of con- or hetero-specifics can influence behaviour and rates of oxygen uptake. Species may differ in these responses.

Hall and Clark,

2016; Nadler

et al., 2016

79.8 Processes of digestion and assimilation of food (so-called specific dynamic action) raises rates of oxygen uptake. SMR is, by definition, measured on fasted animals.

18.8 Should ideally be reported as the start and end dates of data collection for the study. Animals may habituate or acclimate to the laboratory setting, which could affect behaviour and metabolic rate. Body mass or life-stage may also change over time.

73.1 A change of environment may cause endocrine responses with unknown consequences for rates of oxygen uptake. Changes in holding temperature may require time for acclimation to be complete. Various behavioural changes with lab adjustment (e.g. establishment of social hierarchies) may also affect metabolic rates. If animals were bred in the lab this should be stated.

Schulte, 2015

Speers-Roesch

et al., 2018

Snyder et al., 2016

Claireaux and

Chabot, 2016;

Ultsch and

Regan, 2019

Chabot et al., 2016

White et al., 2013

Killen et al., 2014

Sidell et al., 1973;

Sloman et al.

2000

\section{Background respiration}

29 State whether background microbial respiration was measured and accounted for, and if so, method used (e.g. parallel measures with empty respirometer, measurements before and after for all chambers while empty, both) measured at beginning and/or end, state how many slopes and for what duration

67.8 Background microbial respiration can be substantial, especially in small chambers that have a large surface area to volume ratio, when water temperature is warm, or when food or faeces are present in the respirometer. Background respiration must, therefore, be measured and accounted for. In studies which estimate specific dynamic action, it should be mentioned whether excess food and faeces in respirometers where removed.

33.7 If background respiration is low, long measurement durations may be needed to evaluate it accurately. Measuring background respiration at the beginning and end of a trial is required to properly account for gradual increases in microbial activity over time.
Svendsen et al., $2016 a$

Svendsen et al., $2016 a$ 
Table 1. Continued

\begin{tabular}{|c|c|c|c|c|}
\hline Number & Criterion and category & $\begin{array}{l}\text { Prevalence } \\
\text { (\% papers) }\end{array}$ & Description & References \\
\hline 31 & $\begin{array}{l}\text { State how changes in } \\
\text { background respiration were } \\
\text { modelled over time (e.g. linear, } \\
\text { exponential, parallel } \\
\text { measures) }\end{array}$ & 36.5 & $\begin{array}{l}\text { If background respiration changes over time (for example increasing while } \\
\text { fish are held in a chamber), assumptions are required for the form of such } \\
\text { an increase. }\end{array}$ & $\begin{array}{l}\text { Rodgers et al., } \\
\text { 2016; Svendsen } \\
\text { et al., 2016a }\end{array}$ \\
\hline 32 & $\begin{array}{l}\text { Provide level of background } \\
\text { respiration (e.g. as a } \\
\text { percentage of SMR) }\end{array}$ & 22.6 & $\begin{array}{l}\text { This permits evaluation of potential problems with validity of estimates of } \\
\text { metabolic traits. }\end{array}$ & $\begin{array}{l}\text { Svendsen et al., } \\
\text { 2016a }\end{array}$ \\
\hline 33 & $\begin{array}{l}\text { State method and frequency of } \\
\text { system cleaning (e.g. system } \\
\text { bleached between each trial, } \\
\text { UV lamp) }\end{array}$ & 28.4 & $\begin{array}{l}\text { Regular cleaning can help minimise background respiration, especially in } \\
\text { warm water systems. This provides an idea of water quality and the } \\
\text { amount of background respiration that could be expected, if this is not } \\
\text { performed. }\end{array}$ & \\
\hline \multicolumn{5}{|c|}{ Standard or routine metabolic rate } \\
\hline 34 & $\begin{array}{l}\text { Provide acclimation time after } \\
\text { transfer to chamber, or } \\
\text { alternatively, time to reach } \\
\text { beginning of metabolic rate } \\
\text { measurements after } \\
\text { introduction to chamber }\end{array}$ & 62.1 & $\begin{array}{l}\text { At the outset of measures, rates of oxygen uptake will be affected by } \\
\text { handling and possibly confinement stress. }\end{array}$ & $\begin{array}{r}\text { Chabot et al., 2016; } \\
\text { Steffensen, } 1989\end{array}$ \\
\hline 35 & $\begin{array}{l}\text { Provide time period, within a trial, } \\
\text { over which oxygen uptake was } \\
\text { measured (e.g. number of } \\
\text { hours) }\end{array}$ & 84.1 & $\begin{array}{l}\text { SMR may not be reached if the period used to estimate metabolic rate is too } \\
\text { short, for example due to initial handling stress. Periods of spontaneous } \\
\text { activity may also influence metabolic rate estimates if only a few } \\
\text { measurements of oxygen uptake are taken, regardless of the time the fish } \\
\text { are in the respirometer. }\end{array}$ & Chabot et al., 2016 \\
\hline 36 & $\begin{array}{l}\text { State what value was taken as } \\
\text { SMR/RMR (e.g. quantile, } \\
\text { mean of lowest } 10 \% \text {, mean of } \\
\text { all values) }\end{array}$ & 82.5 & $\begin{array}{l}\text { There is no universally accepted method to statistically estimate SMR, and } \\
\text { the exact value considered as SMR may vary with the method chosen. }\end{array}$ & $\begin{array}{l}\text { Chabot et al., 2016; } \\
\text { Harianto et al., } \\
\text { 2019; Morozov } \\
\text { et al., } 2020\end{array}$ \\
\hline 37 & $\begin{array}{l}\text { Provide total number of slopes } \\
\text { measured and used to derive } \\
\text { metabolic rate (e.g. how much } \\
\text { data were used to calculate } \\
\text { quantiles) }\end{array}$ & 33.8 & $\begin{array}{l}\text { Ideally reported as a range of slope numbers across individuals, this permits } \\
\text { evaluation of how accurately SMR might be estimated. }\end{array}$ & Chabot et al., 2016 \\
\hline 38 & $\begin{array}{l}\text { State whether any time periods } \\
\text { were removed from } \\
\text { calculations of SMR/RMR [e.g. } \\
\text { data during acclimation, } \\
\text { periods of high activity (e.g. } \\
\text { daytime)] }\end{array}$ & 57.9 & $\begin{array}{l}\text { Periods when animals were affected by recent handling, or when they } \\
\text { exhibit spontaneous increased activity, may affect estimation of SMR. }\end{array}$ & Chabot et al., 2016 \\
\hline 39 & $\begin{array}{l}\text { Provide } r^{2} \text { threshold for slopes } \\
\text { used for SMR/RMR (or mean } \\
r^{2} \text { ) }\end{array}$ & 33.8 & $\begin{array}{l}\text { By convention, } r^{2} \text { should be above } 0.9 \text {. This convention has been } \\
\text { questioned, so this threshold should be reported. }\end{array}$ & $\begin{array}{l}\text { Chabot et al., 2021; } \\
\text { Steffensen, 1989; } \\
\text { Svendsen et al., } \\
2016 a\end{array}$ \\
\hline 40 & $\begin{array}{l}\text { Provide proportion of data } \\
\text { removed due to being outliers } \\
\text { below } r^{2} \text { threshold }\end{array}$ & 8.8 & $\begin{array}{l}\text { This provides an indication of the quality of the recorded data, since low and } \\
\text { more variable } r^{2} \text { (that would be sorted out as outliers) indicate poor mixing } \\
\text { and/or too large a respirometer-to-animal-volume ratio. }\end{array}$ & Chabot et al., 2021 \\
\hline \multicolumn{5}{|c|}{ Maximum metabolic rate } \\
\hline 41 & $\begin{array}{l}\text { State when MMR was measured } \\
\text { in relation to SMR (i.e. before } \\
\text { or after) }\end{array}$ & 80.8 & $\begin{array}{l}\text { This could be significant for any carry-over effects (for example if } \\
\text { inadequate recovery time was given when measuring SMR after MMR). }\end{array}$ & \\
\hline 42 & $\begin{array}{l}\text { State method used (e.g. critical } \\
\text { swimming speed respirometry, } \\
\text { swim to exhaustion in swim } \\
\text { tunnel, or chase to exhaustion } \\
\text { in tank or respirometer) }\end{array}$ & 87.5 & The method used may affect estimation of MMR. & $\begin{array}{l}\text { Killen et al., 2017; } \\
\text { Norin and Clark, } \\
\text { 2016; Zhang } \\
\text { et al., } 2020\end{array}$ \\
\hline 43 & $\begin{array}{l}\text { State what value was taken as } \\
\text { MMR (e.g. the highest oxygen } \\
\text { uptake rate value after } \\
\text { transfer, average of highest } \\
\text { values) }\end{array}$ & 78.9 & The value chosen may affect the estimated magnitude of MMR. & $\begin{array}{l}\text { Andersson et al., } \\
\text { 2020; Harianto } \\
\text { et al., 2019; } \\
\text { Morozov et al., } \\
2020\end{array}$ \\
\hline 44 & $\begin{array}{l}\text { State length of activity challenge } \\
\text { used for estimating MMR (e.g. } \\
\text { duration and water velocity } \\
\text { increment of swim test, } \\
\text { duration of chase in minutes or } \\
\text { until exhaustion, etc.) }\end{array}$ & 81.5 & Important to ensure that MMR was achieved. & Roche et al., 2013 \\
\hline
\end{tabular}


Table 1. Continued

\begin{tabular}{|c|c|c|c|c|}
\hline Number & Criterion and category & $\begin{array}{l}\text { Prevalence } \\
\text { (\% papers) }\end{array}$ & Description & References \\
\hline 45 & $\begin{array}{l}\text { If MMR was measured post- } \\
\text { exhaustion, state whether } \\
\text { further air-exposure was } \\
\text { added after exercise }\end{array}$ & 48.7 & $\begin{array}{l}\text { Air-exposure has been proposed to ensure that MMR is achieved when } \\
\text { measured as excess post-exercise oxygen consumption (EPOC). }\end{array}$ & Roche et al., 2013 \\
\hline 46 & $\begin{array}{l}\text { If MMR was measured post- } \\
\text { exhaustion, provide time until } \\
\text { transfer to chamber after } \\
\text { exhaustion and time to start of } \\
\text { oxygen uptake recording }\end{array}$ & 37.5 & $\begin{array}{l}\text { Important to evaluate whether fish may have recovered some EPOC prior to } \\
\text { measurement. }\end{array}$ & Zhang et al., 2020 \\
\hline 47 & $\begin{array}{l}\text { Provide duration of slopes used } \\
\text { to calculate MMR (e.g. } 1 \mathrm{~min} \text {, } \\
5 \mathrm{~min} \text {, etc.) }\end{array}$ & 49.6 & $\begin{array}{l}\text { Important for evaluating whether MMR may have been under- or } \\
\text { over-estimated (e.g. if the animal has started recovering after an } \\
\text { exhaustive chase or a swim to exhaustion). }\end{array}$ & $\begin{array}{l}\text { Norin and Clark, } \\
\text { 2016; Zhang } \\
\text { et al., } 2020\end{array}$ \\
\hline 48 & $\begin{array}{l}\text { State slope estimation method } \\
\text { for MMR (e.g. rolling } \\
\text { regression, sequential discrete } \\
\text { time frames) }\end{array}$ & 21.4 & Method of estimation can affect the magnitude of MMR. & $\begin{array}{l}\text { Harianto et al., } \\
\text { 2019; Morozov } \\
\text { et al., 2020; } \\
\text { Zhang et al., } 2019\end{array}$ \\
\hline 49 & $\begin{array}{l}\text { State how absolute aerobic } \\
\text { scope and/or factorial aerobic } \\
\text { scope is calculated (i.e. using } \\
\text { raw SMR and MMR, } \\
\text { allometrically mass-adjusted } \\
\text { SMR and MMR, or } \\
\text { allometrically mass-adjusting } \\
\text { aerobic scope itself) }\end{array}$ & 61.9 & $\begin{array}{l}\text { This can affect the magnitude of aerobic scope, and whether the measure is } \\
\text { adjusted for body mass. }\end{array}$ & \\
\hline \multicolumn{5}{|c|}{ Data handling and statistics } \\
\hline 50 & Provide sample size & 85.1 & Important for evaluating the robustness of reported effects. & \\
\hline 51 & $\begin{array}{l}\text { State how oxygen uptake rates } \\
\text { were calculated (software or } \\
\text { script, equation, units, etc.) }\end{array}$ & 77.4 & Important for replication of the study. & \\
\hline 52 & $\begin{array}{l}\text { Confirm that volume (or mass) of } \\
\text { the animal was subtracted } \\
\text { from respirometer volume } \\
\text { when calculating oxygen } \\
\text { uptake rates }\end{array}$ & 53.8 & $\begin{array}{l}\text { Not subtracting animal volume will lead to inaccurate estimates of metabolic } \\
\text { rates, since the actual volume of water from which the animals were taking } \\
\text { up oxygen would be incorrect. For convenience, animal volume is often } \\
\text { assumed to be equal to its body mass (i.e. the animal having a density of } \\
1 \mathrm{~g} \mathrm{ml}^{-1} \text { ). }\end{array}$ & \\
\hline 53 & $\begin{array}{l}\text { Specify whether variation in body } \\
\text { mass was accounted for in } \\
\text { analyses and describe any } \\
\text { allometric body-mass- } \\
\text { correction or adjustment }\end{array}$ & 61.8 & $\begin{array}{l}\text { Important for comparing reported estimates of metabolic rates among } \\
\text { treatment groups, other studies and, in general, animals of different sizes. } \\
\text { Note that reporting mass-specific metabolic rate (i.e. dividing oxygen } \\
\text { uptake of the animal by its mass) usually does not correct for variation in } \\
\text { size, because with a log-log plot, the relationship between metabolic rate } \\
\text { (or oxygen uptake) and body mass will have a slope of } b-1 \text {, with } b \text { being } \\
\text { the allometric exponent for whole-animal metabolic rate. Thus, unless } \\
b=1.0, \text { mass-specific metabolic rate will remain dependent on body mass. }\end{array}$ & $\begin{array}{l}\text { Schmidt-Nielsen, } \\
1975\end{array}$ \\
\hline
\end{tabular}

data acquisition devices and logging software, as well as different options for respirometer construction and virtually every other component used in intermittent-flow respirometry. Each choice made when gathering equipment and setting up the apparatus can potentially have an impact on the results obtained. Consequently, depending on the exact setup, data reliability may be affected. Furthermore, details of the equipment choices are essential for attempts at replication.

\section{Measurement conditions}

It is important to include details about conditions at the time at which measurements are made. These include details of exogenous factors such as temperature, oxygenation, lighting and any sensory stimulation, such as from visual interactions with experimenters or with conspecifics in adjacent respirometers. Such factors may directly affect rates of animal oxygen uptake (Claireaux and Chabot, 2016; Clarke and Johnston, 1999; Nadler et al., 2016). Other important conditions include endogenous factors, such as the feeding state of the experimental animal and their adjustment period to experimental conditions; these aspects can also influence oxygen uptake (Chabot et al., 2016).

\section{Background respiration}

Over prolonged periods, throughout the alternating closed and flush phases, microbes may proliferate on the surfaces of respirometry systems. The magnitude of background microbial respiration can therefore be substantial and must be quantified and corrected for. There are several different methods that can be used, and the exact approach must be carefully documented.

\section{Measurement of SMR (or RMR)}

There are several methodological details that are specific to the measurement of either SMR or RMR (Box 1). As for the choice of equipment and setup, there are a range of possibilities; experimental details that can vary across studies must be clearly communicated. After data are collected, there are various ways to calculate values for SMR and RMR (Box 1). The trait value may be affected by the 
specific method chosen, and some approaches may even be inappropriate for the experimental conditions used or the species under study.

\section{Measurement of MMR}

As for the measurement of SMR and RMR, there are a variety of specific details that are unique to the measurement and processing of data for MMR (Box 1), most of which concern how increased rates of oxygen uptake are achieved. These details must be recorded to allow for accurate evaluation of the results and replicability of the experiment.

\section{Data handling and analysis}

There are several additional factors regarding basic data handling and processing that may affect final values or statistical analyses and that must, therefore, be provided to ensure that the data are interpretable and replicable.

\section{Survey of the existing literature}

Following the development of the checklist introduced above, we conducted a quantitative analysis of previous reporting of the checklist criteria among studies using aquatic intermittent-flow respirometry in fishes. Our aim was to highlight specific areas in which reporting of methodological details can be improved. For details of how this literature survey was conducted, please see Appendix 1.

Our analysis of 202 published papers (with $n=123$ of these including data for MMR in addition to SMR or RMR), from 19932021, shows that reporting of methods has been relatively poor and inconsistent, including in our own published articles. Reporting showed a slight negative correlation with journal impact factor (Clarivate Analytics 2020, where available for each journal; GLMM, $P=0.031$ ), but there was tremendous variation around this relationship, indicating that problems with reporting persist throughout the published literature (Fig. S2; Table S2). There was some evidence of an improvement in reporting over the last few decades (Fig. 2; GLMM, effect of year, $P=0.001$ ), but the reporting of methods for intermittent-flow respirometry generally remains inadequate, with extreme variation in reporting quality among recent studies (Fig. 2). Although specific papers often scored highly within a particular category, all papers failed to report several criteria across categories. There was wide variation in reporting frequency of criteria within categories, with some specific criteria being consistently under-reported (Table 1; Fig. 3). The lack of consistency across studies is undoubtedly due to the lack of any established guidelines for reporting the methodological details of intermittent-flow respirometry.

In addressing specific methodological details, it is important for researchers to be as clear and explicit as possible, to eliminate any chance of misinterpretation. Another common problem is that articles often refer to multiple prior studies for methodological details, but these references would contain inconsistent or contradictory information. The use of inaccurate or vague phrasing can also cause confusion, misunderstanding of what methods were performed and, potentially, the spread of incorrect information and terminology. Of course, although the use of a checklist for methodological details should improve the reporting of methods for intermittent-flow respirometry, it is ultimately dependent upon researchers to use clear and unambiguous language when describing methods. Our findings on the reporting of various aspects of respirometry measurements across the literature are discussed in more detail below.

\section{Equipment, materials and setup}

In our survey, only $71 \%$ of articles clearly specified the body mass of animals at the time of respirometry, as opposed to upon arrival at the lab or during holding conditions. Body size affects both minimum and maximum metabolic rates (Jerde et al., 2019; Killen et al., 2016) and temporal variation in body mass will affect metabolic rate estimation. This information is also required when assessing the ratio between respirometer volume and animal mass, a measure that was only explicitly provided in $12 \%$ of studies (criterion 4 ).

There were several other criteria that were consistently underreported. For example, only $48 \%$ of papers surveyed provided any mention of whether mixing was performed inside the respirometers and how it was accomplished (criterion 3). Proper mixing of the water in respirometers is critical to homogenise oxygen concentrations throughout chambers, and accurately measuring oxygen uptake is simply not possible without effective mixing. Criteria relating to mixing circuit tubing (criteria 4, 5, 6 and 7) were only mentioned in $12-21 \%$ of papers, despite this being a key component of intermittent-flow respirometry methods that use an external mixing circuit (Rodgers et al., 2016; Svendsen et al., 2016a). In some respirometer designs, mixing may be achieved by using an impellor or stir-bar, but in situations where an external pump is used for mixing, any tubing used in a mixing circuit needs to be as clean as possible, as short as possible and made of relatively gas-impermeable material. Any respiration from microbes adhering to the surface, or gas exchange across the tubing, could have confounding effects that need to be corrected for or avoided. Moreover, the volume of the mixing circuit must be included in the calculation of respirometer volume and, therefore, animal oxygen uptake rate (criterion 7).

\section{Measurement conditions}

Numerous criteria pertaining to conditions during measurement were reported infrequently. Temperature or photoperiod during holding conditions were often given without explicit reference to conditions during respirometry, or how temperature conditions were maintained. Metabolic rates of ectothermic animals are profoundly influenced by temperature (Clarke and Johnston, 1999; Schulte, 2015) and photoperiod may affect animal oxygen uptake (Biswas and Takeuchi, 2002); temperature and photoperiod may also interact so that diurnal patterns in oxygen uptake are different at different temperatures (Speers-Roesch et al., 2018). Although many studies measure multiple animals simultaneously during respirometry, with each animal within its own chamber, only $15 \%$ of studies mention whether the animals were visually shielded from each other (criterion 25). This could have various impacts on activity and metabolic rates that could differ among species, depending on their level of sociability or aggression (Killen et al., 2014; Nadler et al., 2016; Ros et al., 2006). Only $19 \%$ of papers reported the total time taken to measure all animals in a study, from the start of the study to the end of the study (criterion 27). This criterion may be especially important for studies with large sample sizes, leading to overlap with breeding seasons or significant changes in mass of small, rapidly growing animals. Only $31 \%$ of studies mentioned the lowest water oxygen concentration that animals were exposed to during respirometer closed phases (criterion 22). If oxygen depletion by the animal actually causes hypoxia during closed phases, this may cause repeated reliance upon anaerobic pathways to meet energy requirements of metabolism, which would then interfere with estimates of metabolic rate that use oxygen uptake as a proxy (Snyder et al., 2016). Additionally, repeated hypoxia may elicit an endocrine stress response or stimulate swimming activity and 


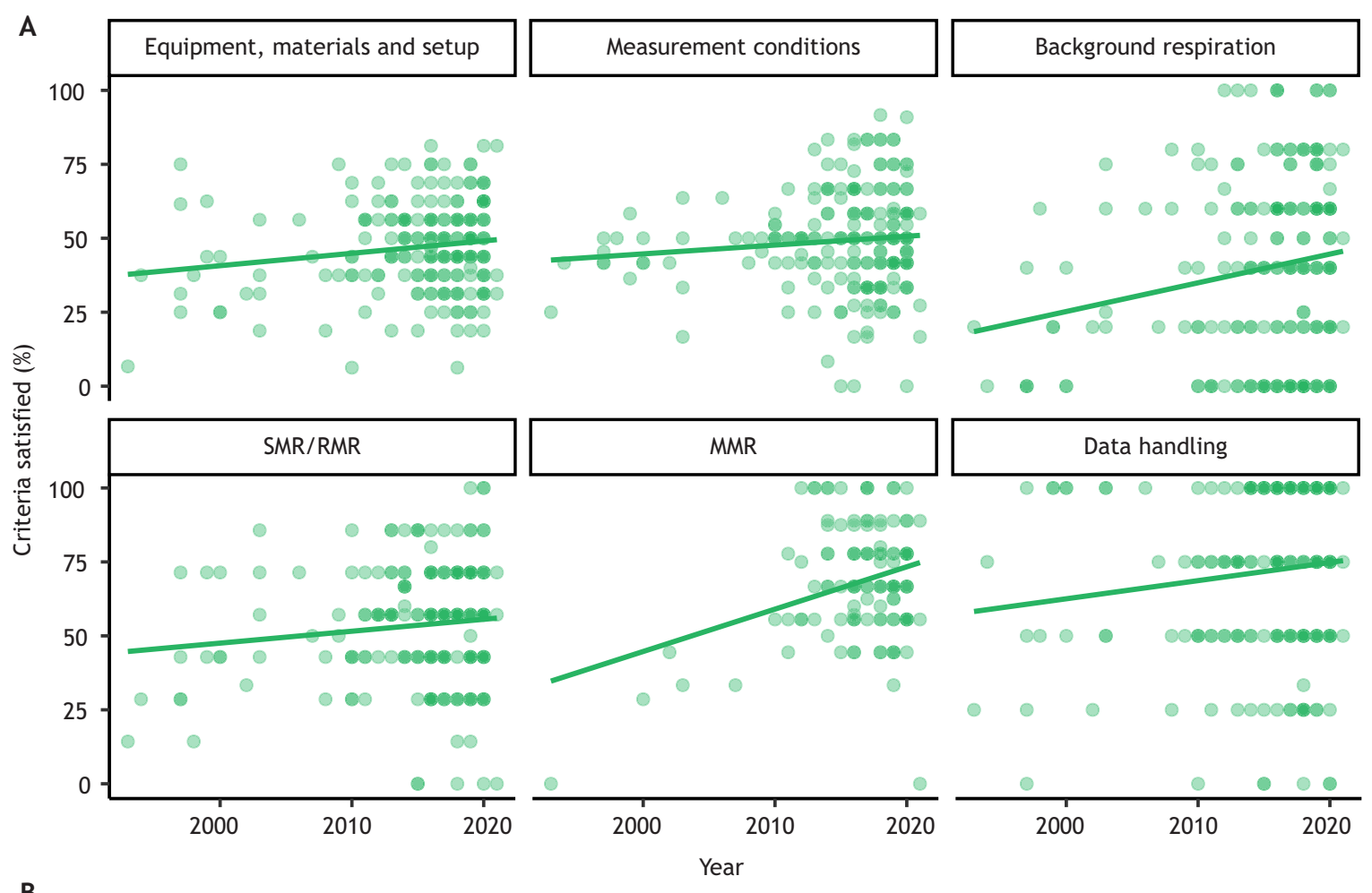

B

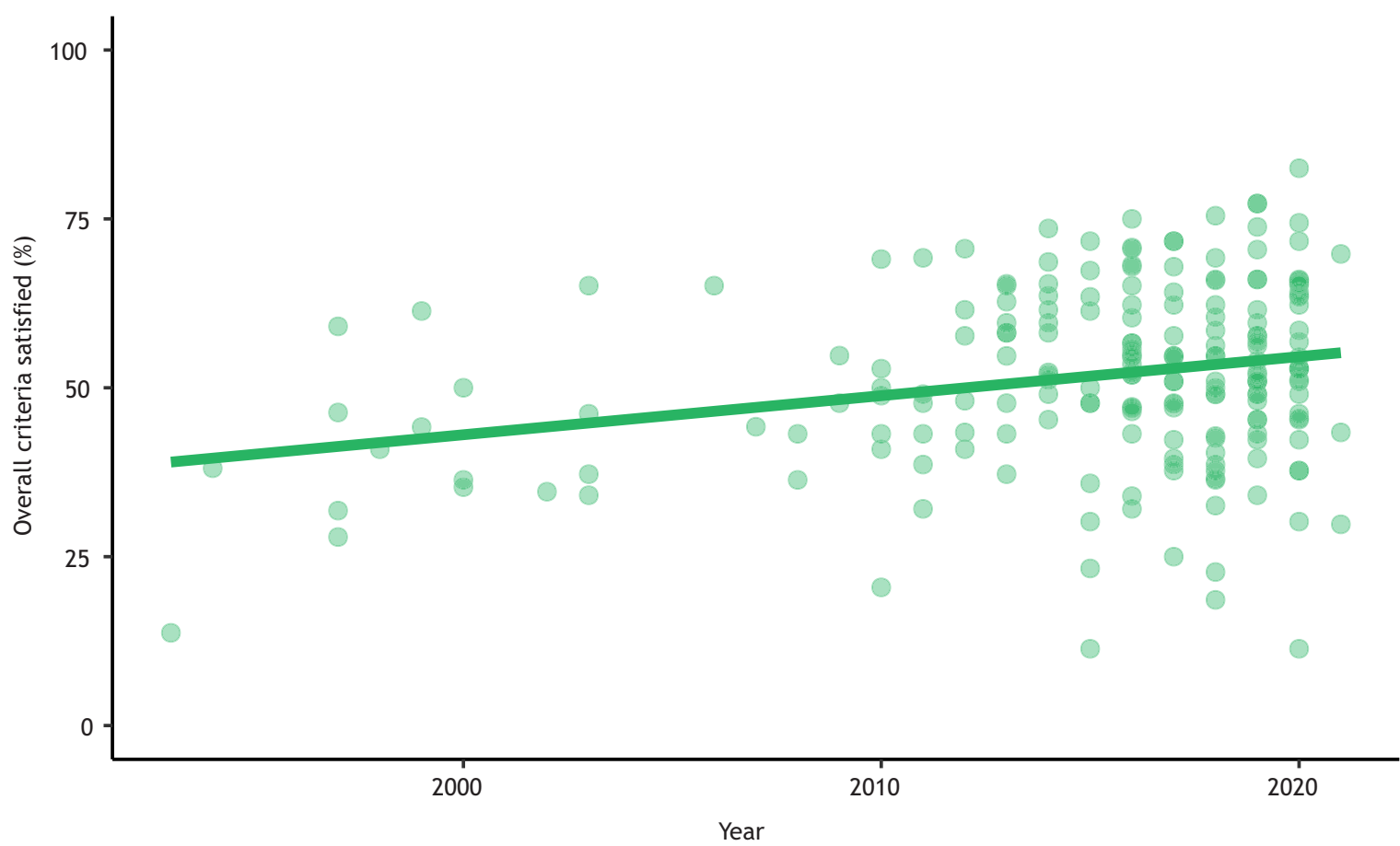

Fig. 2. The percentage of criteria listed in Table 1 that were satisfied in the surveyed papers. Each point represents one paper; solid lines are linear regressions with publication year on the $x$-axis (see Table $\mathrm{S} 2$ for model summary and parameter estimates). Points are partially transparent and so darker shades of green indicate greater numbers of overlapping data points. (A) Criteria sub-divided according to category. (B) Overall percentage of criteria satisfied. The number of studies in each panel is $n=202$, except for the panel for MMR (many papers did not contain data for MMR, see Appendix 1), where $n=123$. Regression equations and $P$-values for effect of year are as follows: Equipment, materials and setup: $y=-797.23 x+0.419$ (year), $P=0.0232$; Measurement conditions: $y=-551.42 x+0.298$ (year), $P=0.154$; Background respiration: $y=-1916.42 x+0.971$ (year), $P=0.00867$; SMR/RMR: $y=-758.29 x+0.403$ (year), $P=0.098$; MMR: $y=-2819.76 x+1.43$ (year), $P=0.0007$; Data handling: $y=-1165.27 x+0.614$ (year), $P=0.079$; Overall: $y=-1113.06 x+0.578$ (year), $P=0.0003$.

increase ventilation frequency, also affecting metabolism and rates of oxygen uptake due to physical activity (Aboagye and Allen, 2014; Killen et al., 2012).

\section{Background respiration}

Overall, criteria associated with measuring background microbial (e.g. bacterial) oxygen uptake were the most inconsistently reported 


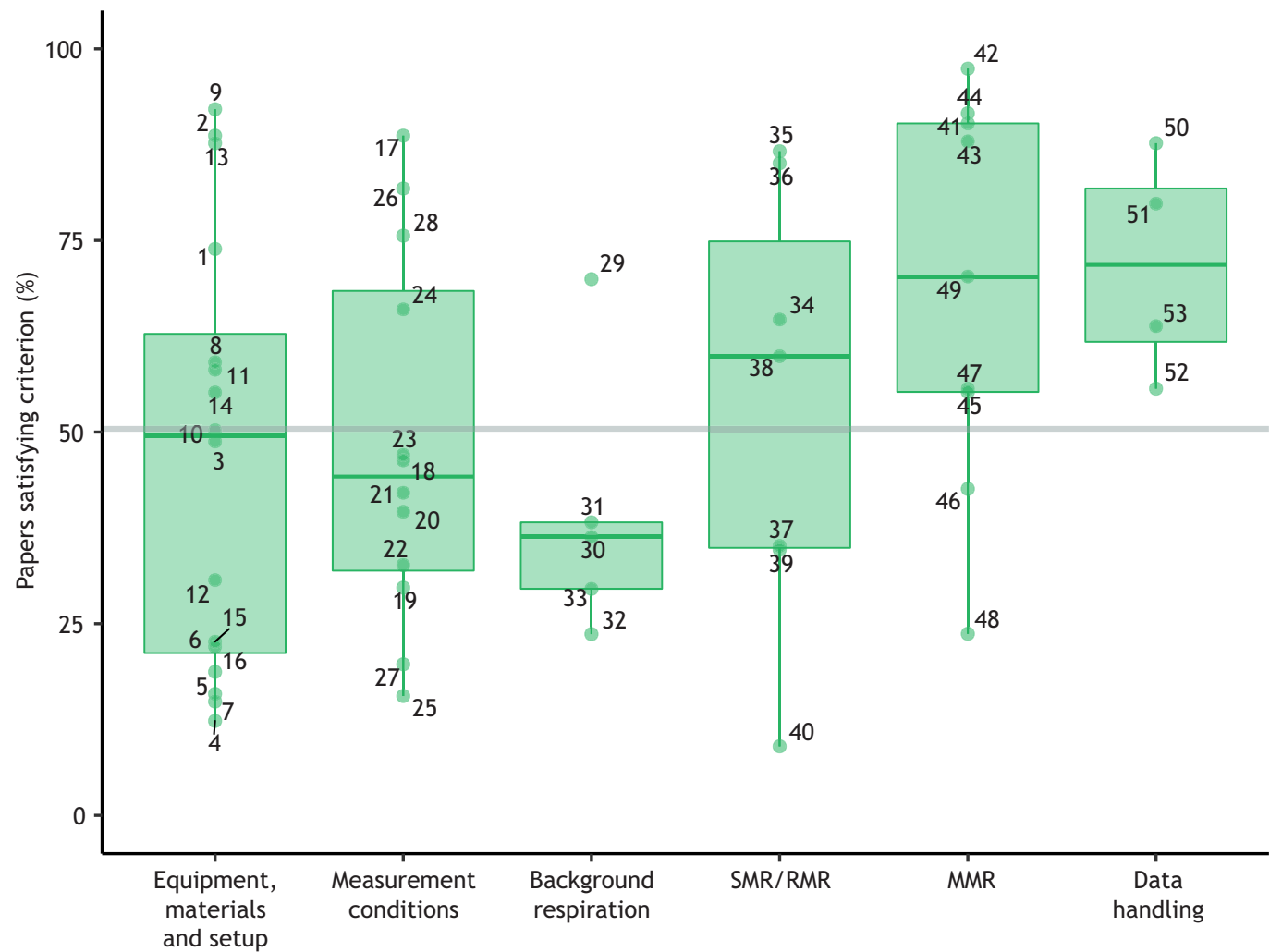

Fig. 3. The percentage of papers that referred to the specific criteria listed in Table 1. Each point represents one criterion; numbered labels correspond to criteria numbering in Table 1. Criteria for each category were scored across $n=202$ studies, except for the MMR category, where $n=123$ (several papers did not include data for MMR, see Appendix 1). The grey line is the overall average across all criteria. Boxplot lower and upper hinges represent the 25th and 75th percentiles, respectively; the horizontal line within the box represents the median; the length of whiskers represents the range of data points between either the upper or lower hinge and $1.5 \times$ the difference between the 25th and 75 th percentiles.

among studies (GLMM, effect of category, $P<0.0001)$. In fact, more than $30 \%$ of papers surveyed did not mention whether any form of background microbial respiration measurement was performed or accounted for. This is a critical oversight because the amount of background respiration and the exact way it is measured, or incorrectly accounting for rates of background oxygen uptake, can greatly impact estimates of animal metabolic rates (Rodgers et al., 2016; Svendsen et al., 2016a).

A large proportion of remaining papers failed to describe how background respiration was controlled (e.g. by cleaning of respirometry chambers and setup), precisely how it was measured and accounted for, or the proportion of animal metabolism that it represented. Simply measuring background respiration prior to respirometry trials does not account for how it might increase with time of residence of animals in a respirometer. Background respiration should either be measured in parallel with animal respiration, using empty chambers, or should be measured at the start and finish of a trial, with a model decided upon for how it may have changed (increased) over time. In fact, parallel measurements of background respiration in empty chambers should ideally be combined with measurements at the start and finish of a trial in all chambers, as the temporal development of microbial respiration in chambers with animals may differ from that without animals. This is especially likely in studies where animals have been fed in the respirometers or before being placed in respirometers (e.g. studies that estimate the metabolic costs incurred during digestion and assimilation of nutrients, so called 'specific-dynamic action'; McLean et al., 2018). Without appropriate details on background respiration, it is extremely difficult to assess data validity. This is, therefore, a methodological element that researchers must perform properly and report clearly.

\section{Estimating SMR/RMR and MMR}

There are several criteria unique to the estimation of either SMR/ RMR or MMR that were often not reported. Regarding SMR/RMR, the total number of oxygen uptake rate measurements (i.e. number of closed phases) used in the derivation of the metabolic rate estimate (criterion 37) was reported in only $34 \%$ of studies. Methods for statistically estimating SMR, for example, including the use of quantiles or frequency distributions, require a large number of repeated measures, and so the total number of slopes used in their derivation should be provided, as should any slopes that were disregarded during acclimation to the respirometer or periods of increased activity (criterion 38; including whether such periods were included in quantile- or frequency distribution-based methods of calculating SMR; Chabot et al., 2016). Note that there are excellent $\mathrm{R}$ packages available e.g. respR (https://github.com/ januarharianto/respR; Harianto et al., 2019) and FishResp (https:// CRAN.R-project.org/package=FishResp; Morozov et al., 2020) that are specifically designed for calculation of oxygen uptake rates using data obtained through intermittent-flow respirometry. These packages include various options for estimation of SMR, RMR and MMR, as well as corrections for background respiration. Wider use of these packages would help facilitate replication and reproducibility.

Although reporting for MMR was relatively good when compared with the other criteria categories (appearing in a mean of $61 \%$ of papers across criteria), there were still important details 
that were often neglected. For example, when measuring oxygen uptake immediately after exhaustion, many studies did not report whether the animal was exposed to air before placement in the chamber (criterion 45). The time taken to initiate measurements of oxygen uptake (e.g. in seconds, after the cessation of exercise) was also often not provided (criterion 46). Finally, only $21 \%$ of papers described the specific method of slope estimation for determining MMR. This is important because data processing procedures can bias estimates of MMR (Zhang et al., 2020), including the duration of the slope used to estimate MMR and the specific method of determining the maximum rate of oxygen uptake during recovery after exercise (criterion 48). Our survey revealed that both criteria were relatively underreported, but given emerging awareness of their importance, it is vital that authors provide these details going forward.

\section{Data handling}

Additional basic information about data processing was also frequently under-reported. For example, while $85 \%$ of papers clearly reported study sample size, several did not provide this fundamental information or did so in a way that was unclear (i.e. provided total animals used in study but not specific treatments). Only $54 \%$ of papers specifically mentioned that animal volume was subtracted from total respirometer volume, a step in data processing that is required to obtain accurate rates of oxygen uptake. Finally, only $62 \%$ of papers explicitly stated whether they used any form of body size adjustment or correction for rates of oxygen uptake in analyses or described their methods for doing so. Due to the strong correlation between body size and whole-animal metabolic rate (and corresponding oxygen uptake), this information is key for ensuring data interpretability.

\section{Conclusions}

As discussed above, the reporting of methods for intermittent-flow respirometry has generally been inconsistent and insufficient. However, we hope the development of guidelines and the availability of a reporting checklist will facilitate systematically clear and accurate reporting of methods. Reporting needs to be improved for all the general areas we examined and for specific criteria, but especially when considering measurement of background respiration and details of the mixing circuit. Although we suggest that intermittent-flow respirometry should be the method of choice whenever possible, elements of the checklist related to methodological details, measuring conditions and background respiration are also relevant to the general use of other forms of respirometry to estimate metabolic rate in aquatic animals.

As authors that frequently use intermittent-flow respirometry, we appreciate the challenges in reporting the numerous details required for adequate replication and interpretation of data collected using this technique. We acknowledge that our own work has been prone to the same reporting deficiencies we have described in this Commentary and, indeed, many of our own papers are contained within our literature survey. We suggest that authors use our downloadable checklist (Table S1) to concisely address all the criteria outlined in the current paper and that authors make a completed version of this form available as a supplementary table in future published papers. This checklist can also be used to help carefully plan important details when designing setups for the collection of oxygen uptake data.

It is more important than ever to ensure the collection and reporting of reliable and replicable data, as metabolic rates are increasingly becoming a focus for understanding the ability of animals to cope with environmental and climate change. Accurate reporting of methodologies is particularly important in cases where data may be used to inform conservation efforts. The availability of a checklist of important methodological details should also be useful to new researchers entering this rapidly developing field, and we hope that our checklist will be a valuable resource to both new and experienced researchers in this area.

\section{Appendix 1 \\ Methods for the literature survey and scoring of criteria Literature survey and criteria scoring}

Focussing on studies with fish, we performed a survey of the literature to determine variation in the reporting of methods and the extent to which various criteria are (or are not) reported. Using Web of Science and Google Scholar in April 2021, we used the topic search terms: (1) 'fish AND respirometry AND intermittent'; and (2) "[fish AND ("standard metabolic rate" OR "resting metabolic rate" OR "routine metabolic rate") AND "maxim* metabolic rate"]'. This survey was not meant to be exhaustive but was meant to be representative of the methodological reporting across research using fish intermittent-flow respirometry as a whole. Articles were excluded from further analysis if they were review articles, metaanalyses or any other study that did not estimate metabolic rates of fish using intermittent-flow respirometry. Studies that estimated metabolic rates while the animal was in a swim-tunnel were also not included in the survey (i.e. we only included studies where measurements of oxygen uptake were performed in static respirometry chambers). In total, 202 studies from 71 journals were assessed from between the years 1993 and 2021 (data are available at Mendeley Data: https://doi.org/10.17632/fky5n2nt9x.2; and are also included with this submission). This consisted of 123 studies that measured both SMR (or RMR) and MMR, and 79 studies that measured or SMR (or RMR) only, without MMR.

Each study was scored for whether they satisfied each criterion in the checklist. Studies were awarded a point for a given criterion if they gave a clear, unambiguous description of that methodological detail, without the need for reader assumptions or calculations. Importantly, scores were not based on the quality of a methodology itself - they were simply based on whether a given detail was provided. For example, if a paper had stated that the respirometer was made of Swiss cheese, the criterion 'provide material of respirometer' (criterion 8; Table 1) would be considered satisfied and a point would be awarded, without judgement of whether Swiss cheese is an appropriate material for respirometer construction. Methodological details for specific criteria were considered present if they were provided in the main article text, figures, tables or supplementary material, or in references to previously published work. When there were references to multiple prior studies for a given criterion, a point was not given if those prior sources provided inconsistent or contradictory descriptions. In some cases, the absence of a specific criterion made it impossible to assess other associated criteria, in which case a value of NA was assigned to criteria that were unable to be scored, and those instances were not included in calculating the mean score for that paper or in calculating the mean prevalence of that criteria across papers. Although most studies were evaluated by one scorer, 16 studies were initially evaluated by two scorers each, ensuring consistency across scorers and allowing refinement of criteria phrasing to minimise ambiguity. For each article, we also recorded the title, year of publication and journal (paper titles have been anonymised in the data file at Mendeley Data: https://doi.org/10.17632/fky5n2nt9x.3). 


\section{Statistical analysis}

A generalised linear mixed model (GLMM) with a binomial distribution (logit link) was constructed to examine factors affecting methods reporting across published papers. The score for each criterion per paper ( 0 or 1$)$ was used as the response variable, and criteria category, scaled year, scaled journal impact factor and all interactions among these variables were initially included as explanatory variables. Paper ID (coded anonymously by title) and scorer were included as random effects. Non-significant interactions were dropped sequentially and the model re-run. All analyses were conducted using R v. 4.0.3 (https://www.r-project.org/) using the function glmm in package lme4 (https://CRAN.R-project.org/ package=lme4; Bates et al., 2015). All R scripts are available at Mendeley Data: https://doi.org/10.17632/fky5n2nt9x.3.

\section{Acknowledgements}

The authors are grateful to Denis Chabot, Fredrik Jutfelt, Anna Andreassen, Joëlle Guitard, and an anonymous reviewer for their constructive feedback on an earlier version of this manuscript.

\section{Competing interests}

The authors declare no competing or financial interests.

\section{Author contributions}

Conceptualization: S.S.K.; Methodology: S.S.K., E.A.F.C., D.C., L.Z., T.N., L.C., A.C., A.M., J.J.H.N., M.P., D.J.M.; Data acquisition: S.S.K., E.A.F.C., D.C., L.Z., T.N., L.C., A.C., A.M., J.J.H.N., M.P., D.J.M.; Statistical analysis: L.Z., S.S.K.; Writing - original draft: S.S.K.; Writing - review \& editing: S.S.K., E.A.F.C., D.C., L.Z., T.N., L.C., A.C., A.M., J.J.H.N., M.P., D.J.M.; Visualization: S.S.K., D.C.

\section{Funding}

S.S.K. was supported by a Natural Environment Research Council Standard Grant NE/T008334/1. E.A.F.C. was supported by the Carlsberg Foundation

(Carlsbergfondet CF19-0400). T.N. was supported by funding from the European Union's Horizon 2020 Framework Programme under the Marie Skłodowska-Curie grant agreement no. 713683. L.Z. was supported by the Austrian Science Fund, FWF, Lise Meitner Program (Project M2742 BBL). J.J.H.N. was supported by funding from the European Union's Horizon 2020 Framework Programme under the Marie Skłodowska-Curie grant agreement no. 839039. Open access funding provided by University of Glasgow. Deposited in PMC for immediate release.

\section{Data availability}

Data and scripts are available from Mendeley Data: https://doi.org/10.17632/ fky5n2nt9x.3.

\section{References}

Aboagye, D. L. and Allen, P. J. (2014). Metabolic and locomotor responses of juvenile paddlefish Polyodon spathula to hypoxia and temperature. Comp. Biochem. Physiol. Part A Mol. Integr. Physiol. 169, 51-59. doi:10.1016/j.cbpa. 2013.12.016

Andersson, M. L., Sundberg, F. and Eklöv, P. (2020). Chasing away accurate results: exhaustive chase protocols underestimate maximum metabolic rate estimates in European perch Perca fluviatilis. J. Fish Biol. 97, 1644-1650. doi:10.1111/jfb. 14519

Bates, D., Mächler, M., Bolker, B. and Walker, S. (2015). Fitting linear mixedeffects models using Ime4. J. Stat. Softw. 67, 1-48. doi:10.18637/jss.v067.i01

Biswas, A. K. and Takeuchi, T. (2002). Effect of different photoperiod cycles on metabolic rate and energy loss of fed and unfed adult tilapia Oreochromis niloticus: part II. Fish. Sci. 68, 543-553. doi:10.1046/j.1444-2906.2002.00460.x

Brown, J. H., Gillooly, J. F., Allen, A. P., Savage, V. M. and West, G. B. (2004). Toward a metabolic theory of ecology. Ecology 85, 1771-1789. doi:10.1890/039000

Carp, J. (2012). The secret lives of experiments: methods reporting in the fMRI literature. Neuroimage 63, 289-300. doi:10.1016/j.neuroimage.2012.07.004

Chabot, D., Steffensen, J. F. and Farrell, A. P. (2016). The determination of standard metabolic rate in fishes. J. Fish Biol. 88, 81-121. doi:10.1111/jfb.12845

Chabot, D., Zhang, Y. and Farrell, A. P. (2021). Valid oxygen uptake measurements: using high $r^{2}$ values with good intentions can bias upward the determination of standard metabolic rate. J. Fish Biol. 98, 1206-1216. doi:10.1111/jfb. 14650

Claireaux, G. and Chabot, D. (2016). Responses by fishes to environmental hypoxia: integration through Fry's concept of aerobic metabolic scope. J. Fish Biol. 88, 232-251. doi:10.1111/jfb.12833
Clark, T. D., Sandblom, E. and Jutfelt, F. (2013). Aerobic scope measurements of fishes in an era of climate change: respirometry, relevance and recommendations. J. Exp. Biol. 216, 2771. doi:10.1242/jeb.084251

Clarke, A. and Johnston, N. M. (1999). Scaling of metabolic rate with body mass and temperature in teleost fish. J. Anim. Ecol. 68, 893-905. doi:10.1046/j.13652656.1999.00337.x

Cowger, W., Booth, A. M., Hamilton, B. M., Thaysen, C., Primpke, S., Munno, K., Lusher, A. L., Dehaut, A., Vaz, V. P., Liboiron, M. et al. (2020). Reporting guidelines to increase the reproducibility and comparability of research on microplastics. Appl. Spectrosc. 74, 1066-1077. doi:10.1177/0003702820930292

Fry, F. E. J. (1971). The effect of environmental factors on the physiology of fish. In Fish Physiology, Vol. 6 (ed. W. S. Hoar and D. J. Randall), pp. 1-98. New York: Academic Press.

Hall, A. E., Clark, T. D. (2016). Seeing is believing: metabolism provides insight into threat perception for a prey species of coral reef fish. Anim. Behav. 115, 117-126. doi:10.1016/j.anbehav.2016.03.008

Halsey, L. G., Killen, S. S., Clark, T. D. and Norin, T. (2018). Exploring key issues of aerobic scope interpretation in ectotherms: absolute versus factorial. Rev. Fish Biol. Fish. 28, 405-415. doi:10.1007/s11160-018-9516-3

Harianto, J., Carey, N. and Byrne, M. (2019). respR-An R package for the manipulation and analysis of respirometry data. Methods Ecol. Evol. 10, 912-920. doi:10.1111/2041-210X.13162

Hatton, I. A., Dobson, A. P., Storch, D., Galbraith, E. D. and Loreau, M. (2019) Linking scaling laws across eukaryotes. Proc. Natl. Acad. Sci. USA 116, 21616. doi:10.1073/pnas.1900492116

Holtmann, B., Lagisz, M. and Nakagawa, S. (2017). Metabolic rates, and not hormone levels, are a likely mediator of between-individual differences in behaviour: a meta-analysis. Funct. Ecol. 31, 685-696. doi:10.1111/1365-2435. 12779

Jerde, C. L., Kraskura, K., Eliason, E. J., Csik, S. R., Stier, A. C. and Taper, M. L. (2019). Strong evidence for an intraspecific metabolic scaling coefficient near 0.89 in fish. Front. Physiol. 10, 1166. doi:10.3389/fphys.2019.01166

Jourdan-Pineau, H., Dupont-Prinet, A., Claireaux, G. and McKenzie, D. J. (2010). An investigation of metabolic prioritization in the european sea bass, Dicentrarchus labrax. Physiol. Biochem. Zool. 83, 68-77. doi:10.1086/648485

Jutfelt, F., Norin, T., Ern, R., Overgaard, J., Wang, T., McKenzie, D. J., Lefevre, S., Nilsson, G. E., Metcalfe, N. B., Hickey, A. J. R. et al. (2018) Oxygen- and capacity-limited thermal tolerance: blurring ecology and physiology. J. Exp. Biol. 221, jeb169615. doi:10.1242/jeb.169615

Killen, S. S., Marras, S., Ryan, M. R., Domenici, P. and McKenzie, D. J. (2012). A relationship between metabolic rate and risk-taking behaviour is revealed during hypoxia in juvenile European sea bass. Funct. Ecol. 26, 134-143. doi:10.1111/ j.1365-2435.2011.01920.x

Killen, S. S., Marras, S., Metcalfe, N. B., McKenzie, D. J. and Domenici, P. (2013). Environmental stressors alter relationships between physiology and behaviour. Trends Ecol. Evol. 28, 651-658. doi:10.1016/j.tree.2013.05.005

Killen, S. S., Mitchell, M. D., Rummer, J. L., Chivers, D. P., Ferrari, M. C. O., Meekan, M. G. and McCormick, M. I. (2014). Aerobic scope predicts dominance during early life in a tropical damselfish. Funct. Ecol. 28, 1367-1376. doi:10.1111/ 1365-2435.12296

Killen, S. S., Glazier, D. S., Rezende, E. L., Clark, T. D., Atkinson, D., Willener, A. S. T. and Halsey, L. G. (2016). Ecological influences and morphological correlates of resting and maximal metabolic rates across teleost fish species. Am. Nat. 187, 592-606. doi:10.1086/685893

Killen, S. S., Norin, T. and Halsey, L. G. (2017). Do method and species lifestyle affect measures of maximum metabolic rate in fishes? J. Fish Biol. 90, 1037-1046. doi:10.1111/jfb.13195

Kleiber, M. (1947). Body size and metabolic rate. Physiol. Rev. 27, 511-541. doi:10.1152/physrev.1947.27.4.511

Klimant, I., Meyer, V. and Kühl, M. (1995). Fiber-optic oxygen microsensors, a new tool in aquatic biology. Limnol. Oceanogr. 40, 1159-1165. doi:10.4319/lo.1995.40. 6.1159

Mathot, K. J., Dingemanse, N. J. and Nakagawa, S. (2019). The covariance between metabolic rate and behaviour varies across behaviours and thermal types: meta-analytic insights. Biol. Rev. 94, 1056-1074. doi:10.1111/brv.12491

McLean, S., Persson, A., Norin, T. and Killen, S. S. (2018). Metabolic costs of feeding predicatively alter the spatial distribution of individuals in fish schools. Curr. Biol. 28, 1144-1149.

Metcalfe, N. B., Van Leeuwen, T. E. and Killen, S. S. (2016). Does individual variation in metabolic phenotype predict fish behaviour and performance? J. Fish Biol. 88, 298-321. doi:10.1111/jfb.12699

Michel, M. C., Murphy, T. J. and Motulsky, H. J. (2020). New author guidelines for displaying data and reporting data analysis and statistical methods in experimental biology. J. Pharmacol. Exp. Ther. 372, 136. doi:10.1124/jpet.119. 264143

Morozov, S., McCairns, R. J. S. and Merilä, J. (2020). FishResp: R package and GUI application for analysis of aquatic respirometry data. Conserv. Physiol. 7, coz003. doi:10.1093/conphys/coz003 
Nadler, L. E., Killen, S. S., McClure, E. C., Munday, P. L. and McCormick, M. I. (2016). Shoaling reduces metabolic rate in a gregarious coral reef fish species. J. Exp. Biol. 219, 2802. doi:10.1242/jeb.139493

Nelson, J. A. (2016). Oxygen consumption rate v.rate of energy utilization of fishes: a comparison and brief history of the two measurements. J. Fish Biol. 88, 10-25

Norin, T. and Clark, T. D. (2016). Measurement and relevance of maximum metabolic rate in fishes. J. Fish Biol. 88, 122-151. doi:10.1111/jfb.12796

Norin, T. and Gamperl, A. K. (2018). Metabolic scaling of individuals vs. populations: evidence for variation in scaling exponents at different hierarchical levels. Funct. Ecol. 32, 379-388. doi:10.1111/1365-2435.12996

Norin, T. and Metcalfe, N. B. (2019). Ecological and evolutionary consequences of metabolic rate plasticity in response to environmental change. Philos. Transact. R. Soc. B Biol. Sci. 374, 20180180. doi:10.1098/rstb.2018.0180

Palacios, M. M., Killen, S. S., Nadler, L. E., White, J. R. and McCormick, M. I. (2016). Top predators negate the effect of mesopredators on prey physiology. J. Anim. Ecol. 85, 1078-1086. doi:10.1111/1365-2656.12523

Pörtner, H.-O., Bock, C. and Mark, F. C. (2017). Oxygen- and capacity-limited thermal tolerance: bridging ecology and physiology. J. Exp. Biol. 220, 2685 doi:10.1242/jeb.134585

Roche, D. G., Binning, S. A., Bosiger, Y., Johansen, J. L. and Rummer, J. L. (2013). Finding the best estimates of metabolic rates in a coral reef fish. J. Exp. Biol. 216, 2103-2110. doi:10.1242/jeb.082925

Rodgers, G. G., Tenzing, P. and Clark, T. D. (2016). Experimental methods in aquatic respirometry: the importance of mixing devices and accounting for background respiration. J. Fish Biol. 88, 65-80. doi:10.1111/jfb.12848

Rolfe, D. F. and Brown, G. C. (1997). Cellular energy utilization and molecular origin of standard metabolic rate in mammals. Physiol. Rev. 77, 731-758. doi:10.1152/ physrev.1997.77.3.731

Ros, A. F. H., Becker, K. and Oliveira, R. F. (2006). Aggressive behaviour and energy metabolism in a cichlid fish, Oreochromis mossambicus. Physiol. Behav. 89, 164-170. doi:10.1016/j.physbeh.2006.05.043

Schmidt-Nielsen, K. (1975). Scaling in biology: the consequences of size. J. Exp. Zool. 194, 287-307. doi:10.1002/jez.1401940120

Schulte, P. M. (2015). The effects of temperature on aerobic metabolism: towards a mechanistic understanding of the responses of ectotherms to a changing environment. J. Exp. Biol. 218, 1856. doi:10.1242/jeb.118851

Sidell, B. D., Wilson, F. R., Hazel, J. and Prosser, C. L. (1973). Time course of thermal acclimation in goldfish. J. Comp. Physiol. 84, 119-127. doi:10.1007/ BF00697602
Sloman, K. A., Motherwell, G., O'Connor, K. I. and Taylor, A. C. (2000). The effect of social stress on the Standard Metabolic Rate (SMR) of brown trout, Salmo trutta. Fish Physiol. Biochem. 23, 49-53. doi:10.1023/A:1007855100185

Snyder, S., Nadler, L. E., Bayley, J. S., Svendsen, M. B. S., Johansen, J. L., Domenici, P. and Steffensen, J. F. (2016). Effect of closed v. intermittent-flow respirometry on hypoxia tolerance in the shiner perch Cymatogaster aggregata. J. Fish Biol. 88, 252-264. doi:10.1111/jfb.12837

Speers-Roesch, B., Norin, T. and Driedzic, W. R. (2018). The benefit of being still: energy savings during winter dormancy in fish come from inactivity and the cold not from metabolic rate depression. Proc. R. Soc. B Biol. Sci. 285, 20181593 doi:10.1098/rspb.2018.1593

Steffensen, J. F. (1989). Some errors in respirometry of aquatic breathers: how to avoid and correct for them. Fish Physiol. Biochem. 6, 49-59. doi:10.1007/ BF02995809

Steffensen, J. F., Johansen, K. and Bushnell, P. G. (1984). An automated swimming respirometer. Comp. Biochem. Physiol. Part A Physiol. 79, 437-440. doi:10.1016/0300-9629(84)90541-3

Stevens, E. D. (1992). Use of plastic materials in oxygen-measuring systems J. Appl. Physiol. 72, 801-804. doi:10.1152/jappl.1992.72.2.801

Svendsen, M. B. S., Bushnell, P. G. and Steffensen, J. F. (2016a). Design and setup of intermittent-flow respirometry system for aquatic organisms. J. Fish Biol. 88, 26-50. doi:10.1111/jfb.12797

Svendsen, M. B. S., Bushnell, P. G., Christensen, E. A. F. and Steffensen, J. F. (2016b). Sources of variation in oxygen consumption of aquatic animals demonstrated by simulated constant oxygen consumption and respirometers of different sizes. J. Fish Biol. 88, 51-64. doi:10.1111/jfb.12851

Ultsch, G. R. and Regan, M. D. (2019). The utility and determination of $P_{\text {crit }}$ in fishes. J. Exp. Biol. 222, jeb203646. doi:10.1242/jeb.203646

Ultsch, G. R., Ott, M. E. and Heisler, N. (1980). Standard metabolic rate, critical oxygen tension, and aerobic scope for spontaneous activity of trout (Salmo gairdneri) and carp (Cyprinus carpio) in acidified water. Comp. Biochem. Physiol. Part A Physiol. 67, 329-335. doi:10.1016/S0300-9629(80)80004-1

White, C. R., Schimpf, N. G. and Cassey, P. (2013). The repeatability of metabolic rate declines with time. J. Exp. Biol. 216, 1763-1765. doi:10.1242/jeb.076562

Zhang, Y., Gilbert, M. J. H. and Farrell, A. P. (2019). Finding the peak of dynamic oxygen uptake during fatiguing exercise in fish. J. Exp. Biol. 222, jeb196568. doi:10.1242/jeb.196568

Zhang, Y., Gilbert, M. J. H. and Farrell, A. P. (2020). Measuring maximum oxygen uptake with an incremental swimming test and by chasing rainbow trout to exhaustion inside a respirometry chamber yields the same results. J. Fish Biol. 97 28-38. doi:10.1111/jfb.1431 